\title{
Dynamic model of batch enzymatic reactive distillation for \\ the production of R-2-pentyl butyrate
}

\section{SUPPORTING INFORMATION}

Michat Blatkiewicz **, Fynn Mißfeldt ${ }^{\ddagger}$, Irina Smirnova

Hamburg University of Technology, Institute of Thermal Separation Processes, Eißendorfer Straße 38 (O), 21073 Hamburg

\footnotetext{
${ }^{*}$ Corresponding author, email: michal.blatkiewicz@tuhh.de

$\$$ These authors contributed equally
} 


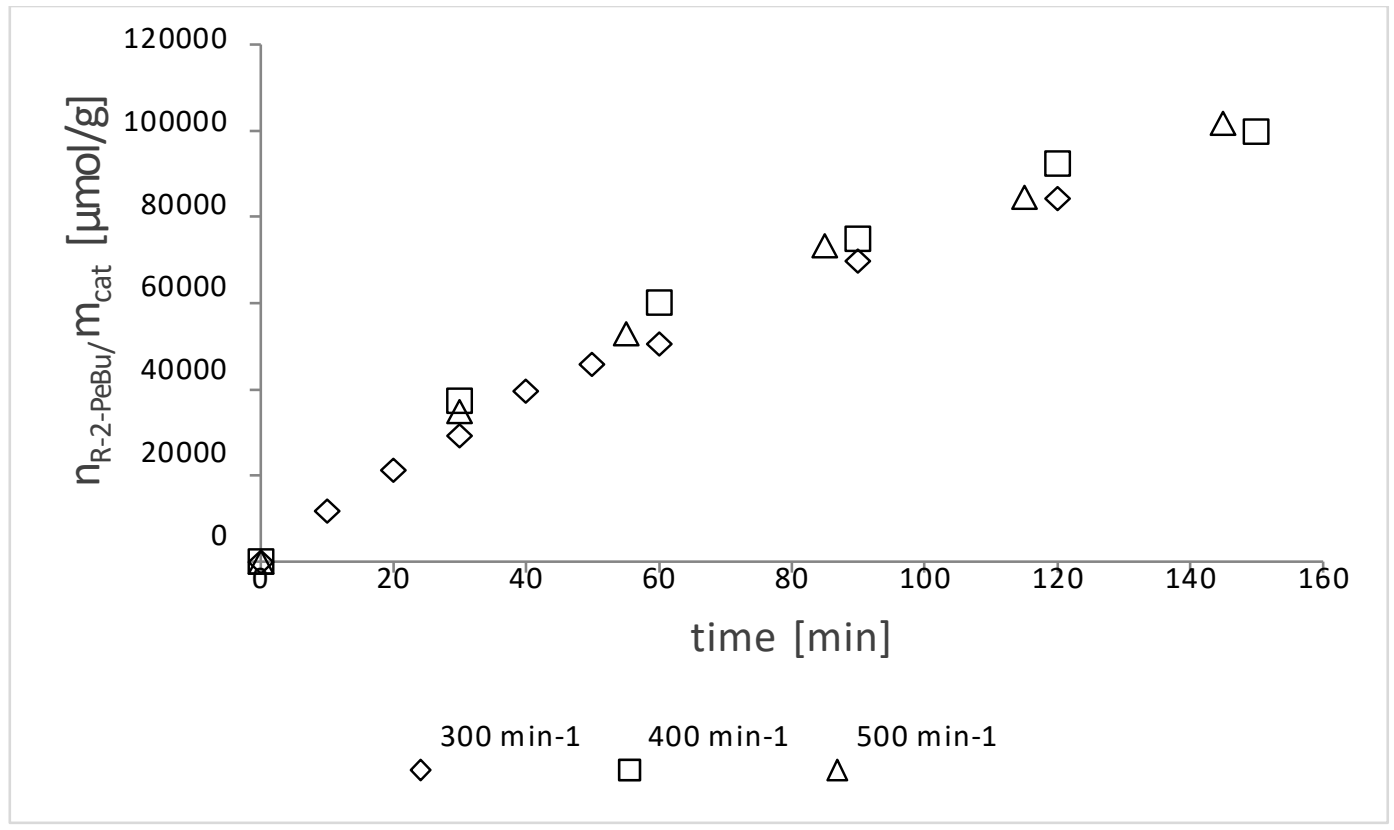

Figure S1: Production of R-2-PeBu with varying stirring speeds in kinetic measurement setup at $60{ }^{\circ} \mathrm{C}$ with a starting composition of $\mathrm{xEtBu}=0.5, \mathrm{XR}-2-\mathrm{PeOH}=0.25, \mathrm{xS}-2-\mathrm{PeOH}=0.25$

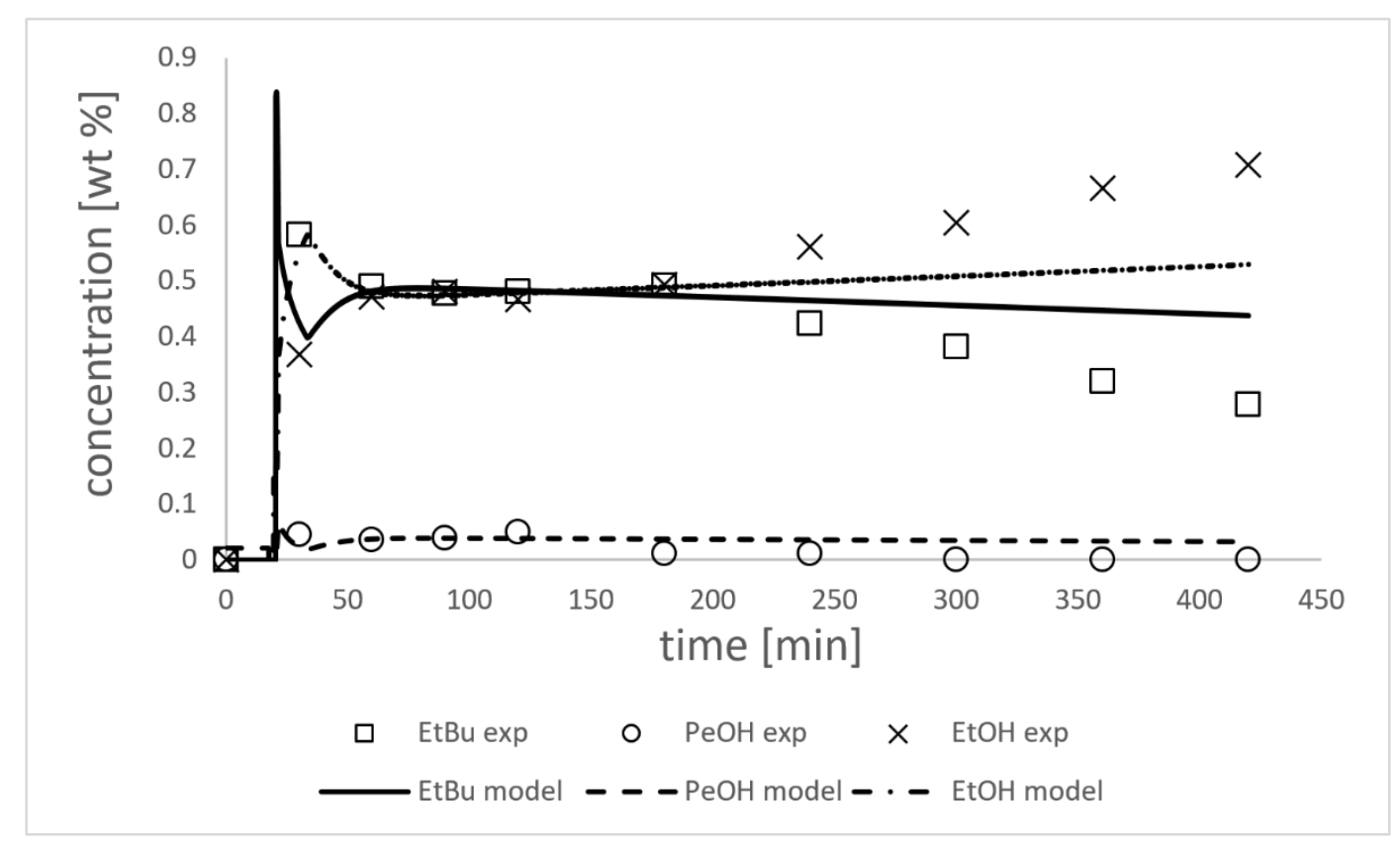

Figure S2: Reactants' concentrations in the distillate stream over time with simulated reflux ratio set at 10 for the whole process 


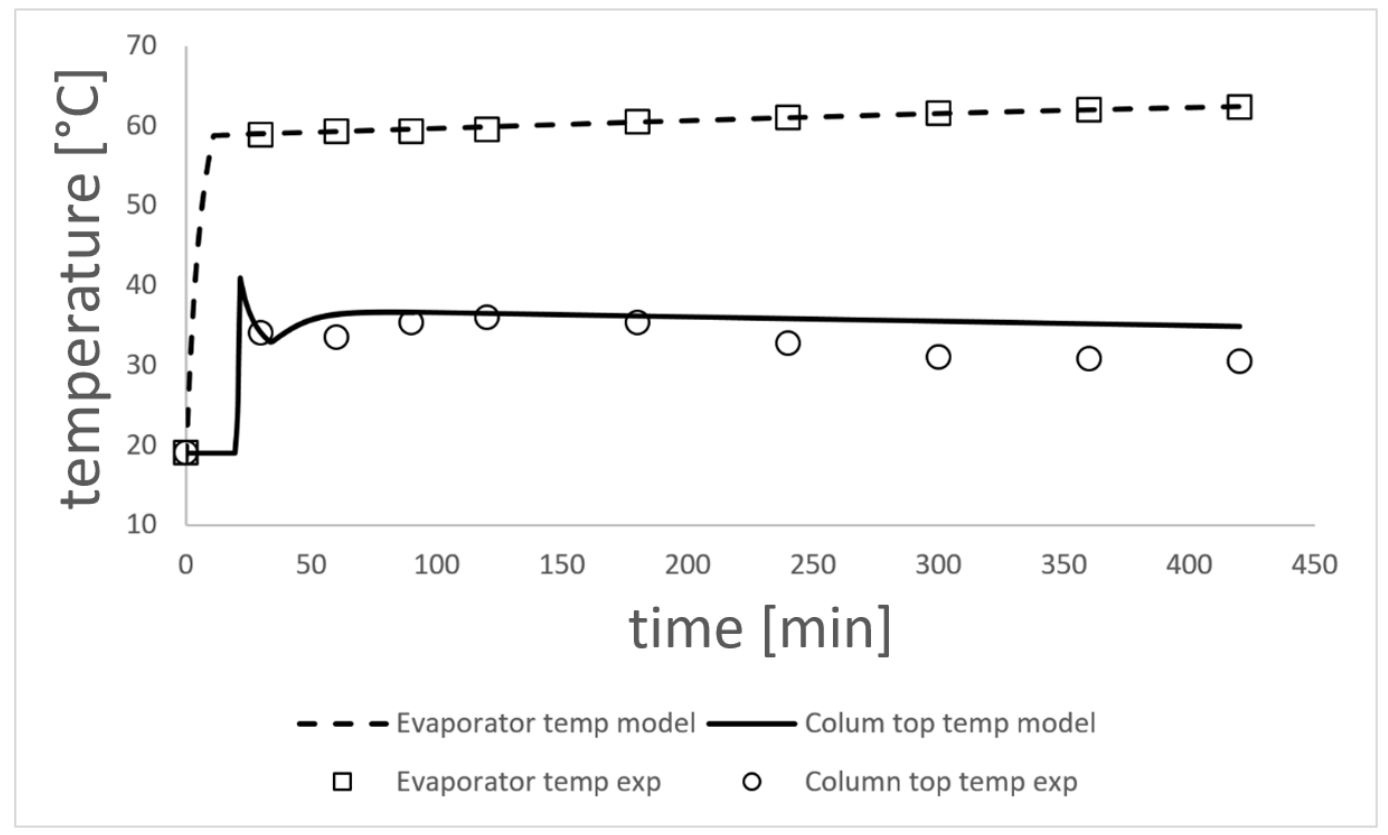

Figure S3: Temperatures of the evaporator and the vapor at the top of the column over time with simulated reflux ratio set at 10 for the whole process

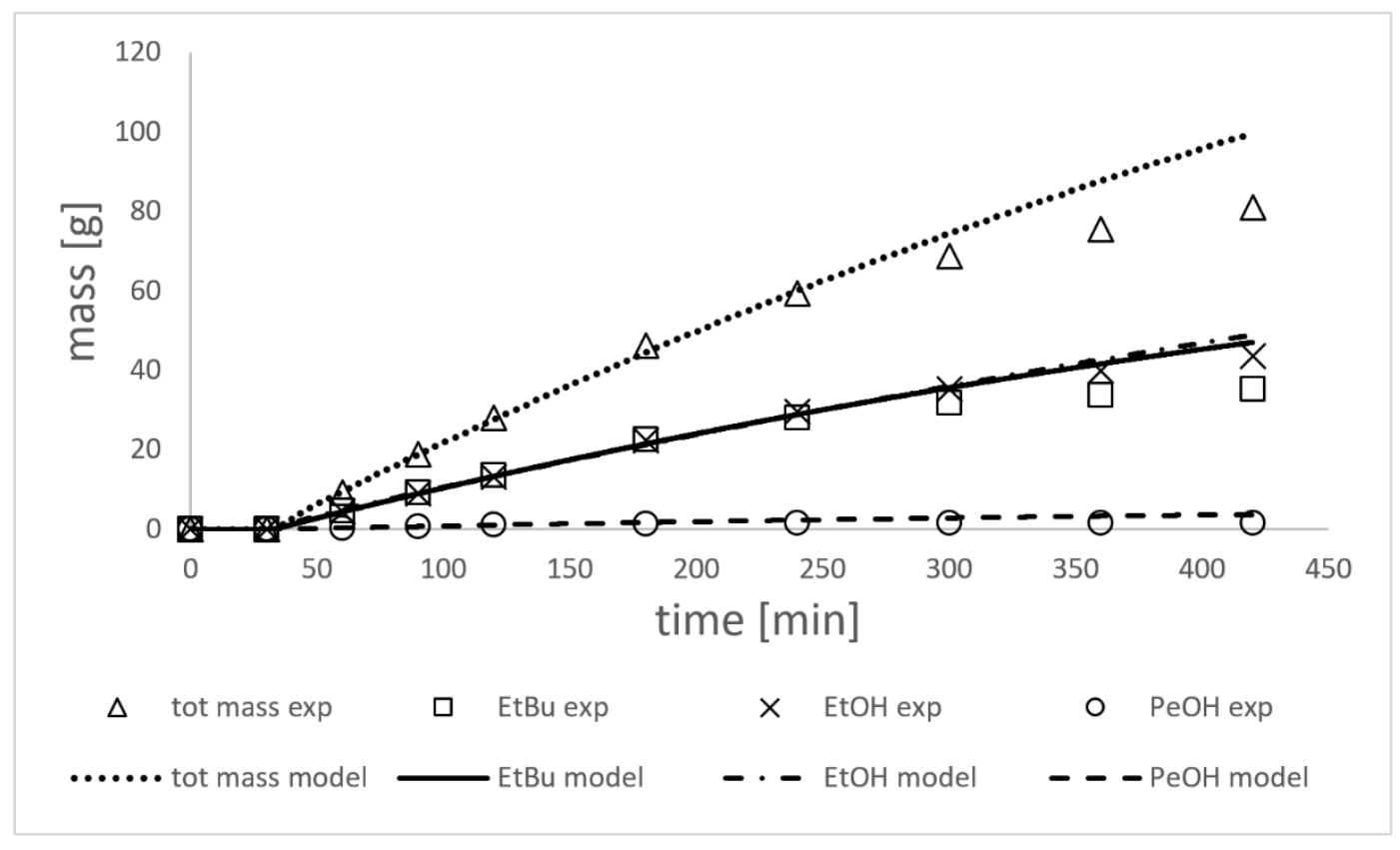

Figure S4: Mass increase in the collection vessel over time with simulated reflux ratio set at 10 for the whole process 